\title{
Long-term respiratory functional results after pneumonectomy ${ }^{\text {is }}$
}

\author{
Luca Luzzi $^{\text {b,* }}$, Sara Tenconi ${ }^{\text {a }}$, Luca Voltolini ${ }^{a}$, Piero Paladini ${ }^{a}$, \\ Claudia Ghiribelli $^{a}$, Maurizio Di Bisceglie ${ }^{a}$, Giuseppe Gotti ${ }^{a}$ \\ ${ }^{a}$ Thoracic Surgery Unit, University Hospital of Siena, Italy \\ b Thoracic Surgery Unit, S.Croce e Carle Hospital, Via Coppino 26, 53100 Cuneo, Italy
}

Received 4 September 2007; received in revised form 10 March 2008; accepted 31 March 2008; Available online 13 May 2008

\begin{abstract}
Introduction: The aim of this study is to evaluate the long-term respiratory outcome of patients who underwent pneumonectomy for non-small cell lung cancer (NSCLC), analysing functional tests. Materials and methods: Twenty-seven consecutive patients who were candidates for pneumonectomy performed spirometry before and at least 24 months after surgery in the same laboratory. Diffusion of carbon monoxide and the most common dynamic and static lung volumes were evaluated in percentage of predicted and compared. Results: A significant inverse correlation was observed between the preoperative FEV1 (\%) and FVC (\%) and their postoperative loss, respectively $r=-641(p<0.0001)$ and $r=-789(p<0.0001)$. Also the correlation between the RV/TLC ratio and the FEV1 loss confirmed a better postoperative outcome in patients with major airway obstruction $(p=0.02)$. To investigate these data, the series were divided into two groups: group A included BPCO patients with a FEV1 lower than $80 \%$, the others were considered group B. Group B showed a significant major postoperative FEV1 (\%) and FVC (\%) impairment, $31 \%$ versus $12 \%, p=0.005$, and FVC (\%) loss, $37 \%$ versus $16 \%(p=0.02)$, meanwhile group A showed a significant major postoperative RV (\%) reduction, $43 \%$ versus $17 \%, p=0.03$. Despite being significantly higher preoperatively in BPCO patients, the RV\% becomes similar between the two groups in the postoperative. Conclusions: In our experience patients with major preoperative airway obstruction who underwent pneumonectomy had lower impairment in FEV1\% at almost one year after surgery than those with normal respiratory function. The resection of a certain amount of non-functional parenchyma associated with the mediastinal shift, with an improvement of the chest cavity for the remaining lung, could give a reduction volume effect in BPCO/emphysematous patients.

(C) 2008 European Association for Cardio-Thoracic Surgery. Published by Elsevier B.V. All rights reserved.
\end{abstract}

Keywords: Pneumonectomy; Lung cancer; Lung resection; BPCO; Pulmonary function test; Lung diffusion capacity

\section{Introduction}

Depending on its extent, pulmonary resection leads to a permanent loss of lung function [1]. Though generally accepted that resection involving not more than one lobe leads to immediate deterioration of lung function parameters and subsequent recovery with little permanent deficit, there is evidence that pneumonectomy causes greater permanent functional loss $[2,3]$. Lung cancer patients are mainly smokers or ex smokers who also suffer from varying degrees of chronic obstructive pulmonary disease (COPD) and/or cardiovascular disease. Advances in surgical and perioperative care have reduced immediate postoperative risks in these patients, extending the possibility of surgical resection to more severe cases as well [4,5]. Although recent studies [6,7] have endeavoured to identify patients at high risk for postoperative mortality and morbidity after lung resection, few reports

\footnotetext{
Presented at the 21st Annual Meeting of the European Association for Cardio-thoracic Surgery, Geneva, Switzerland, September 16-19, 2007.

* Corresponding author. Tel.: +39 0347 8921339; fax: +39 0171642491.

E-mail address: luzzi.luca@virgilio.it (L. Luzzi).
}

consider long-term outcome after pneumonectomy. The aim of this study was to investigate postoperative lung function in a homogeneous group of patients undergoing pneumonectomy in the same centre.

\section{Materials and methods}

All patients undergoing pneumonectomy at the Chest Surgery Unit of Siena University Hospital over an 11-year period (January 1994 to December 2005) were selected from our database. All patients were evaluated and operated on by the same surgical team. The preoperative work-up consisted of clinical assessment and CT scan of brain, chest and upper abdomen; bone scintigraphy was only performed in symptomatic patients. All patients underwent preoperative bronchoscopy. Patients were considered for pneumonectomy if they had adequate cardiac and pulmonary reserve (ppoFEV1 $>0.8 \mathrm{l}$ [8] or a $\mathrm{mVO}_{2}$ greater than $10 \mathrm{ml} / \mathrm{kg} / \mathrm{min}$ [9]). The routine surgical and anaesthesiological procedure included singlelung ventilation with double-lumen endobronchial tube. All patients underwent standard posterolateral thoracotomy. 
Postoperative physiotherapy included early mobilisation and respiratory exercises in all cases. Post-thoracotomy pain control was achieved by continuous intravenous infusion of ketorolac and tramadol. Patients were evaluated by lung function tests (LFTs) before the operation (usually 2-3 days before surgery) and at least 24 months after surgery.

To reduce potentially confounding factors, patients were excluded if they had acute ongoing postoperative lung pathology in the study period, if they performed postoperative LFTs in a different hospital, or if they had preoperative evidence of lobar or total lung atelectasia. LFTs were performed according to European Respiratory Society (ERS) guidelines. Spirometry and body-plethysmography were performed using a Jaeger-Masterlab. The following dynamic and static lung volumes were assessed: FEV1, FVC, FEV1/FVC ratio, TLC, RV and lung carbon monoxide transfer factor (TLCO). An arterial blood sample was taken before surgery and at follow-up and arterial oxygen tension $\left(\mathrm{PaO}_{2}\right)$ and arterial carbon dioxide tension $\left(\mathrm{PaCO}_{2}\right)$ were determined. Impairment of FEV1, FVC, RV and TLC was expressed as percentage decrease:

percentage decrease $=100 \times \frac{(\text { FEV1 preop }- \text { FEV1 postop })}{\text { FEV1 preop }}$

Dynamic and static lung volumes were compared with percentage loss for direct or inverse correlations. Patients were then divided into two groups according to degree of obstruction: group A - patients with FEV $1<80 \%$ and group B - patients with FEV1 $>80 \%$. COPD was defined according to Global Initiative for Chronic Obstructive Lung Disease (GOLD) criteria (FEV1 <80\% and FEV1/FVC <0.7) [10]. Statistical analysis included the $t$-test for independent samples for comparison of means and the bivariate correlation to assess relationships between variables. The statistical software package SPSS 11 (SPSS Inc., Chicago, IL) was used for data processing.

\section{Results}

Between January 1994 and December 2005, 113 patients with non-small cell lung cancer (NSCLC) underwent pneumonectomy at the Chest Surgery Unit, Siena University Hospital. The operations constituted $7.7 \%$ of all major lung resections in the period. Of these patients only 37 performed lung function tests in our department before and after surgery. Four patients of this group had preoperative evidence of lobar (3) or pulmonary (1) atelectasia and were excluded from the study, leaving 33 patients ( 26 male and 7 female, mean age $65 \pm 7$ years), 15 undergoing right (45\%) and 18 left pneumonectomy (55\%). The mean interval between surgery and postoperative LFTs was $31 \pm 6$ months. Only one patient needed more than $24 \mathrm{~h}$ of mechanical ventilation, one patient was revised for bleeding and eight (24\%) suffered postoperative atrial fibrillation and were treated with amiodarone. Preoperative and postoperative respiratory parameters, $\mathrm{PaO}_{2}$ and $\mathrm{PaCO}_{2}$ are summarised in Table 1. All static and dynamic volumes dropped after pneumonectomy. $\mathrm{PaO}_{2}$ was significantly higher (18\%, $85 \pm 10 \mathrm{mmHg}$ vs $76 \pm 10 \mathrm{mmHg}, p=0.002$ ) after surgery.
Table 1

Comparison between pre- and postoperative respiratory parameters

\begin{tabular}{lcll}
\hline Parameters & $\begin{array}{l}\text { Mean preoperative } \\
\text { value }\end{array}$ & $\begin{array}{l}\text { Mean postoperative } \\
\text { value }\end{array}$ & Significance $p$ \\
\hline FEV1 (\%) & 76.55 & 56.37 & 0.0001 \\
FEV1 (l) & 2.12 & 1.52 & 0.0001 \\
FVC (\%) & 90.10 & 63.17 & 0.0001 \\
TLC (\%) & 100.18 & 73.56 & 0.0001 \\
RV (\%) & 125.4 & 91.96 & 0.0001 \\
TLCO (\%) & 79 & 57.35 & 0.0001 \\
paO2 & 74.78 & 85.51 & 0.002 \\
paCO2 & 39.86 & 41.20 & 0.02 \\
\hline
\end{tabular}

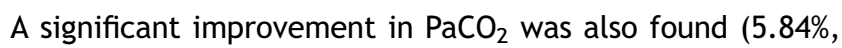
$41 \pm 2,5 \mathrm{mmHg}$ vs $39 \pm 2,8 \mathrm{mmHg}, p=0.02$ ). In an attempt to estimate the reduction in postoperative lung function using preoperative values, we looked for correlations with the above-mentioned percentage decreases. The Spearman correlation test showed a significant correlation $(r=-0.641$; $p<0.0001$ ) between preoperative FEV1 and postoperative percentage decrease in FEV1 (Fig. 1). A similar correlation was found for preoperative FVC $(r=-0.789 ; p<0.0001)$. We also found a correlation $(r=-0.679)$ between preoperative FV1/FVC index (Tiffenau index) and percentage decrease in FEV1 $(p<0.0001)$. For a more appropriate evaluation as proposed by Krost et al. [11] we correlated the FEV1 loss with preoperative COPD index (FEV1\% + Tiffenau) and again found a significant inverse correlation $(r=-0.632 p<0.001$, Fig. 2). A significant direct correlation was found between the Motley index (RV/TLC) and the FEV1 impairment $(r=0.432, p=0.02$, Fig. 3$)$.

Patients were compared based on the type of resection, in the effort to evaluate if there was a different impairment, but no difference in FEV1 loss has been observed between left and right pneumonectomy $(p=0.436)$.

Patients were divided into groups according to presence/ absence of COPD characteristics. Fifteen patients had FEV1

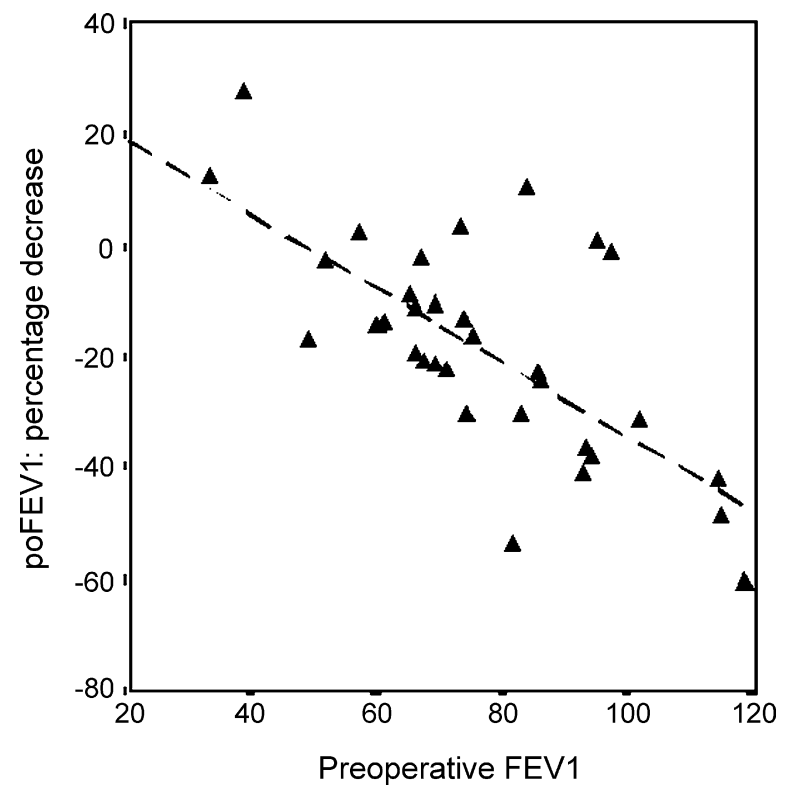

Fig. 1. Correlation between preoperative FEV1 and postoperative percentage decrease in FEV1 after pneumonectomy. 


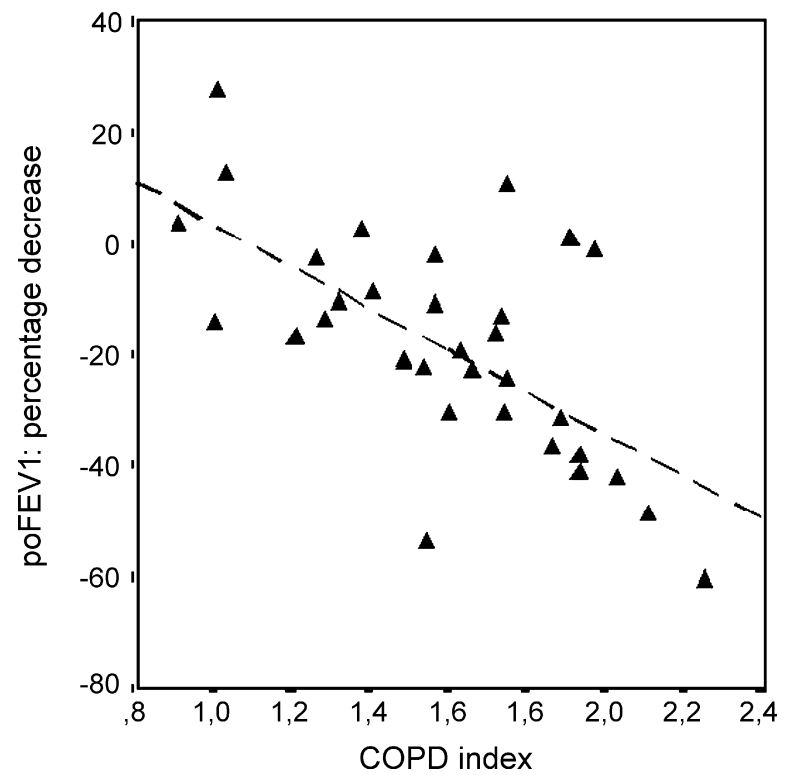

Fig. 2. Correlation between COPD index and percentage decrease in FEV1 after pneumonectomy.

$<80 \%$ of predicted in the preoperative period (group A) and 12 had normal spirometric values (group B). Postoperatively, group B showed a significantly greater percentage decrease in FEV1 (\%) $(31 \%, \pm 19 \%$ vs $12 \%, \pm 11 \%, p=0.005)$ and FVC (\%) (37\%, $\pm 17 \%$ vs $16 \%, \pm 13 \%, p=0.02$ ). Moreover, though patient selection was based on preoperative FEV1, the difference in postoperative FEV1 was not significant between the two groups (Fig. 4). The difference in FVC between the two groups was significant preoperatively $(p<0.0001)$ but not postoperatively (Fig. 5). Group A showed a significantly greater reduction in $\mathrm{RV}(\%)$ postoperatively $(43 \%, \pm 19 \%$ vs $17 \%, \pm 9, p=0.03$ ) than group B. Although preoperatively

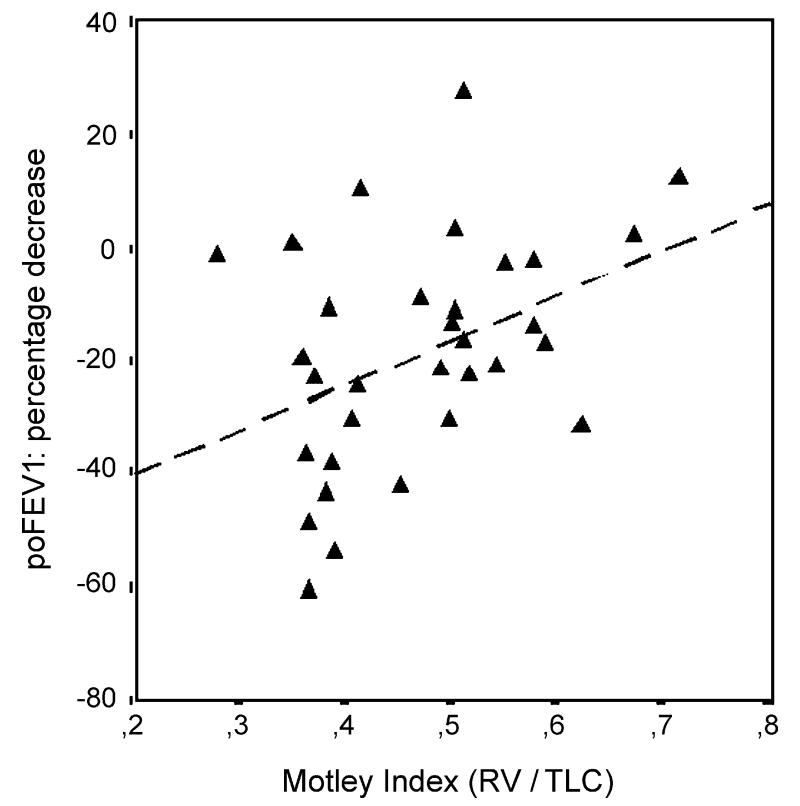

Fig. 3. Correlation between Motley index and percentage decrease in FEV1 after pneumonectomy.

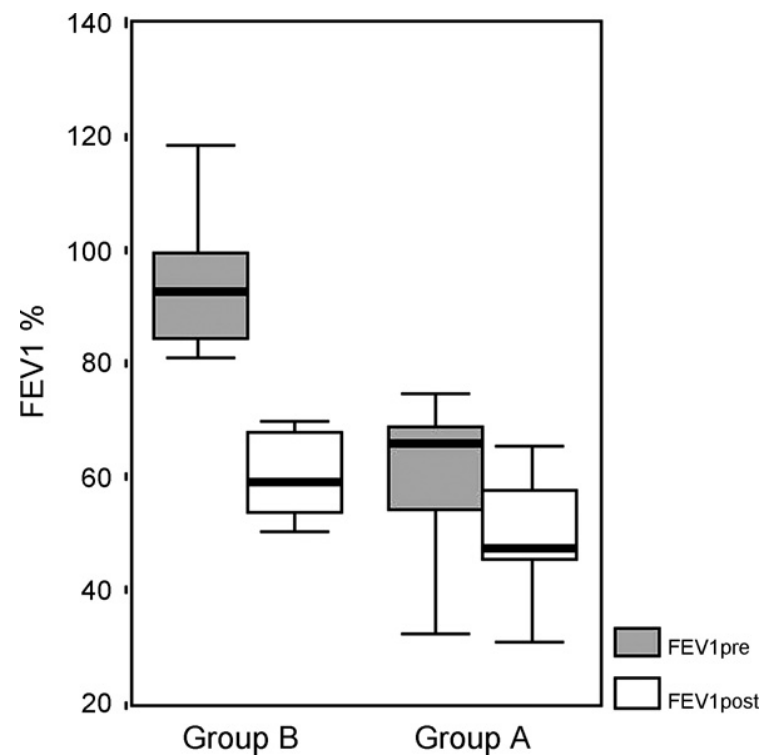

Fig. 4. Pre- and postoperative FEV1 according to preoperative diagnosis of COPD.

there was a significant difference in RV (\%) between the two groups (105\%, $\pm 23 \%$, in group B vs $137 \%$, $\pm 38 \%$, in group A, $p=0.008)$, the difference was less in the postoperative period $(76 \%, \pm 18 \%$ vs $103 \%, \pm 31 \%, p=0.03)$ with a mean value in group A that was about normal (Fig. 6).

In an attempt to understand adaptation of the remaining lung to the new cavity, we compared the Motley index (RV/ TLC) before and after surgery in the two groups. This index, expression of lung hyperinflation, was significantly different between the two groups in the preoperative period $(0.39 \mathrm{vs}$ $0.52, p=0.001)$, but not significant in the postoperative period $(0.46$ vs $0.49, p=0.39$, Fig. 7$)$.

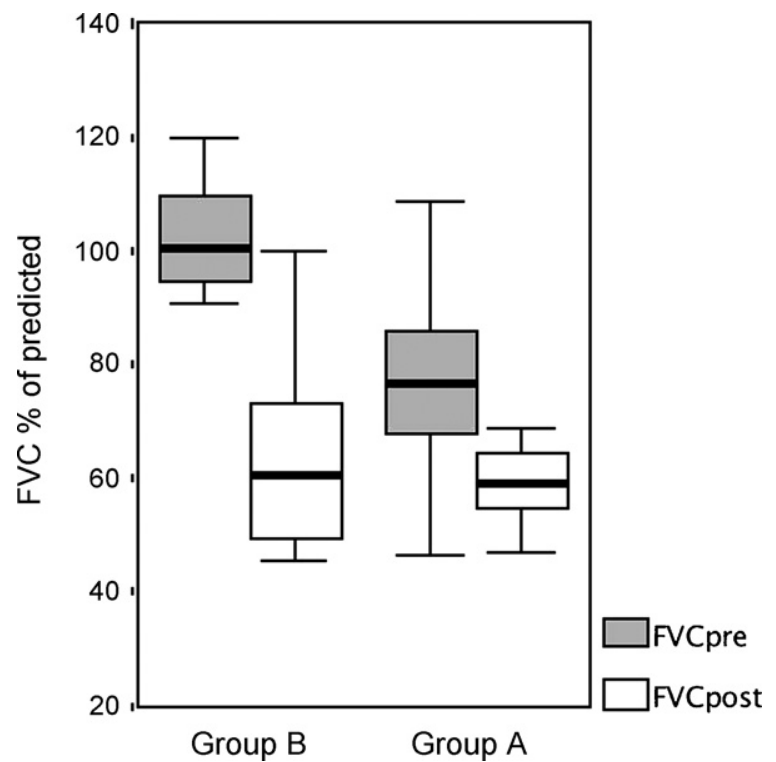

Fig. 5. Pre- and postoperative FVC according to preoperative diagnosis of COPD. 


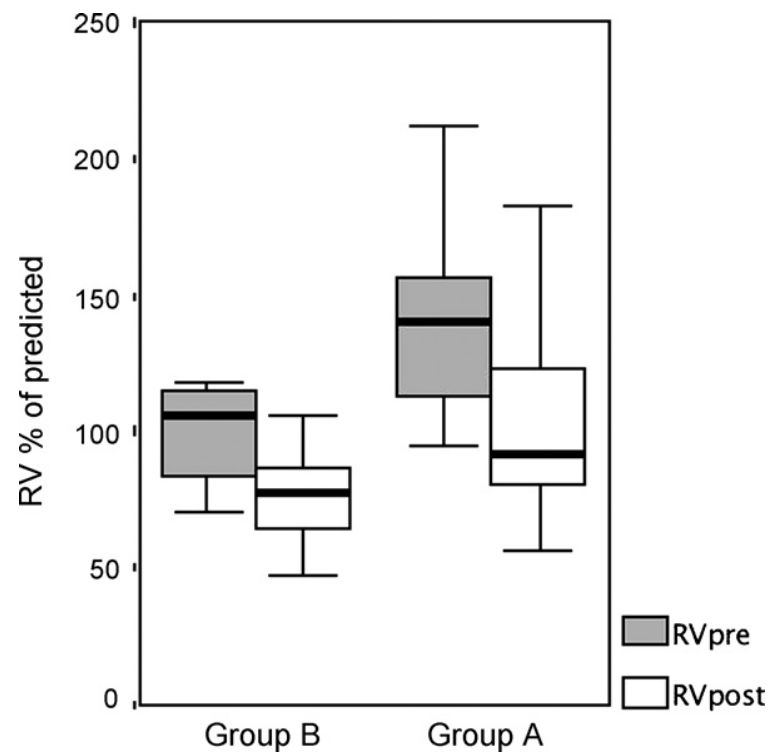

Fig. 6. Pre- and postoperative RV according to preoperative diagnosis of COPD.

\section{Discussion}

Since the first pneumonectomy was performed more than 65 years ago, much has been learned about postpneumonectomy status [12]. Improvements in operating techniques, perioperative support and perioperative screening have decreased morbidity and mortality after pneumonectomy in the course of time [13].

Our study investigated the long-term functional results of pneumonectomy in patients who survived more than 12 months after surgery. Although all dynamic and static respiratory parameters were significantly reduced after pneumonectomy, the percentage reduction was not homogeneous for all patients. The inverse correlation between preoperative FEV1 and FVC and their reduction revealed that

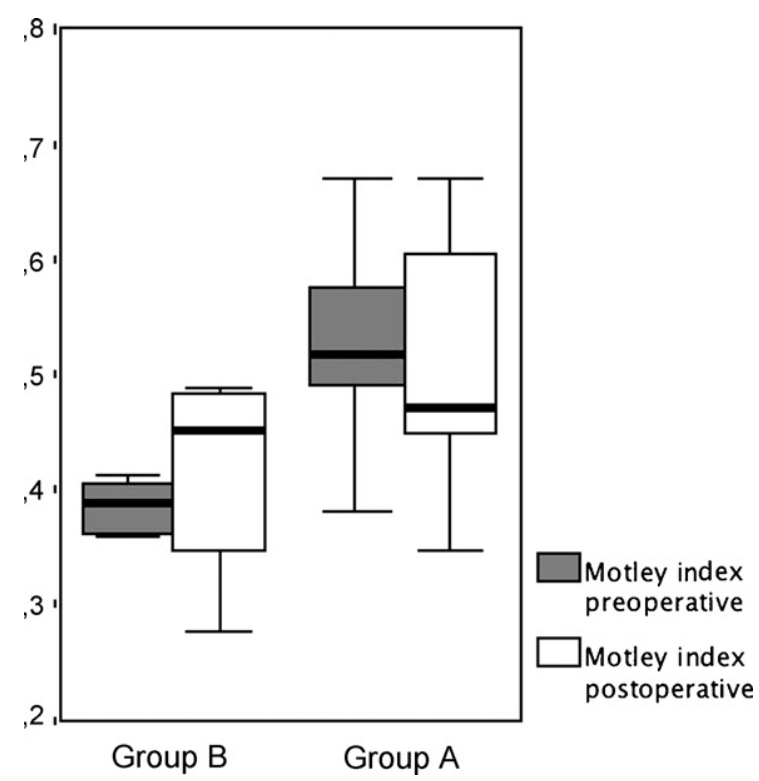

Fig. 7. Pre- and postoperative parenchymal inflation, expressed by Motley index, according to preoperative diagnosis of COPD. patients with lower preoperative FEV1 and FEV1/FVC ratio were less likely to lose lung function after pneumonectomy and were able to improve it in the long term [14]. The correlation between the more accurate COPD index and decline in FEV1 also showed greater percentage decrease in FEV1 in patients with normal preoperative lung function. This result was confirmed comparing decline in FEV1 in the two groups. A similar result has been reported in a recent study by Kushilbe et al. who argued that lung resection involving upper lobes has a different functional result in patients with more compromised preoperative respiratory function, because in these cases the loss of parenchyma has a greater lung volume reduction effect [15]. Other authors [16] also reported a decrease in FEV1 after lung resection inversely correlated to the preoperative FEV1.

Probably, postoperative FEV1 impairment is more related to the amount of functional tissue removed than to the percentage of parenchyma resected. In particular Beccaria et al. have observed a strict correlation between the predicted postoperative FEV1 (ppoFEV1) and the actual postoperative FEV1 (poFEV1) at 6 months in patients after lobectomy but not in patients who underwent pneumonectomy; in these cases the ppoFEV1 underestimated the actual poFEV1 by an average of $500 \mathrm{ml}$ [17]. Beccaria's results confirm the discordance between functional and anatomical parenchymal privation after pneumonectomy that may explain why patients with lower COPD index have a minor postoperative functional impairment. Moreover, the remodelling of the chest cavity after pneumonectomy should have different effects between patients with emphysema and patients with normal parenchyma. In an attempt to explain this difference we argued that the mediastinal shift in the first 24 months after surgery causes an improvement of the remaining chest cavity leading to a lung volume reduction effect in COPD/emphysematous patients. In obstructed patients, mediastinal shift could relieve lung hyperinflation and airway conductance thus enabling expiration of a greater volume in the first second, despite a loss of vital capacity due to resection. Reduction of hyperinflation achieves, at best, respiratory muscle work as it happens in patients who undergo lung volume reduction surgery [18]. This mechanism does not occur in patients with normal parenchyma; in such cases, the residual lung is prone to vicariate emphysema, as demonstrated experimentally [12]. The improvement in Motley index, as an indicator of hyperinflation, in normal patients after pneumonectomy and its concomitant reduction in COPD patients, confirms the hypothesis of relief of hyperinflation in the residual lung in the latter patients.

Despite these intriguing conclusions, this retrospective study has many limitations. Actually, LFTs were performed in a relatively wide range of time and not all patients were investigated as regarding to smoking cessation or use of BPCO therapeutics devices after surgery. Moreover, the study is based only on functional parameters and does not take into account subjective symptoms like dyspnoea and work tolerance. Of course, all patient included in the selection were previously considered eligible for surgery according to literature [19], thus excluding very compromised BPCO subjects. Finally, preoperative perfusion scans seem to reach a more accurate evaluation of functional parenchyma of the resected lung $[20,21]$. For this reason we recently started a 
prospective study in which we are enrolling all patients undergoing pneumonectomy.

\section{Acknowledgment}

We would like to thanks $\mathrm{Dr}$ Roberto Pellegrino and $\mathrm{Dr}$ Alberto Terzi for their valuable contribution in the interpretation of the results of this article.

\section{References}

[1] Bolliger CT, Jordan P, Solér M, Stulz P, Tamm M, Wyser Ch, Gonon M, Perruchoud AP. Pulmonary function and exercise capacity after lung resection. Eur Respir J 1996;9:415-21.

[2] Ali MK, Mountain CF, Ewer MS, Johnston D, Haynie TP. Predicting loss of pulmonary function after pulmonary resection for bronchogenic carcinoma. Chest 1980;77:337-42.

[3] Loddenkemper R, Gabler A, Gobel D. Criteria of functional operability in patients with bronchial carcinoma: preoperative assessment of risk and prediction of postoperative function. Thorac Cardiovasc Surg 1983;31: 334-7.

[4] Reilly Jr JJ. Evidence based preoperative evaluation of candidates for thoracotomy. Chest 1999;116:474S-6S.

[5] Olsen GN. Physiology of lung resection. Chest 1998;113:1438-9.

[6] Rocco G. Outcome of lung surgery: what patients don't like [editorial]. Chest 2000;117:1531-2.

[7] Wyser C, Stulz P, Solèr M, Tamm M, Muller-Brand J, Habicht J, Parruchoud AP, Bollinger CT. Prospective evaluation of an algorithm for the functional assessment of lung resection candidates. Am J Respir Crit Care Med 1999;159:1450-6.

[8] Harpole DH, Liptay MJ, DeCamp MM, Mentzer SJ, Swanson SJ, Sugarbaker DJ. Prospective analysis of pneumonectomy: risk factors for major morbidity and cardiac dysrhythmias. Ann Thorac Surg 1996;61:977-82.
[9] Bollinger CT, Jordan P, Soler M, Stulz P, Gradel E, Skarvan K, Elsasser S, Gonom M, Wyser C, Tamm M. Exercise capacity as predictor of postoperative complications in lung resection candidates. Am J Respir Crit Care Med 1995;151:1472-80.

[10] Glaab T, Banik N, Rutschmann OT, Wenker M. National survey of guidelinecompliant COPD management among pneumologists and primary care physicians. COPD 2006;3(3):141-8.

[11] Korst RJ, Ginsberg RJ, Ailawadi M, Bains MS, Burt ME, Downey RJ, Rush VW, Stover D. Lobectomy improves ventilatory function in selected patients with severe COPD. Ann Thorac Surg 1998;66:898-902.

[12] Kopec SE, Irwin RS, Umali-Torres C, Balikian JP, Conlan AA. The postpneumonectomy state. Chest 1998;114:1158-84.

[13] Algar FJ, Alvarez A, Salvatierra A, Baamonde C, Aranda JL, Lopez-Pujol FJ. Predicting pulmonary complications after pneumonectomy for lung cancer. Eur J Cardiothorac Surg 2003;23:201-8.

[14] Hirdes JJ, Bosh MW. Pneumonectomy in pulmonary tuberculosis without thoracoplasty. J Thorac Surg 1955;30:719-39.

[15] Kushibe K, Takahama M, Tojo T, Kawaguchi T, Kimura M, Taniguchi S. Assessment of pulmonary function after lobectomy for lung cancer upper lobectomy might have the same effect as lung volume reduction surgery. Eur J Cardiothorac Surg 2006;29:886-90.

[16] Boushy SF, Billing DM, North LB, Helgason AH. Clinical course related to preoperative and postoperative pulmonary function in patients with bronchogenic carcinoma. Chest 1971;59:383-91.

[17] Beccaria M, Corsico A, Fulgoni P, Zoia MC, Casali L, Orlandoni G, Cerveri I. Lung cancer resection. The predicting postsurgical outcomes should include long-term functional results. Chest 2001;120:37-42.

[18] Cooper JD, Patterson GA. Lung volume reduction surgery. Semin Thoracic Cardiovasc Surg 1996;8:52-60.

[19] Pierce RJ, Copland JM, Sharpe K, Barter CE. Preoperative risk evaluation for lung cancer resection: predicted preoperative pulmonary procedure as predictor of surgical mortality. Am J Respir Crit Care Med 1994;150: 947-55.

[20] Mazzone PJ, Arroliga AC. Lung cancer: preoperative evaluation of the lung resection candidate. Am J Med 2005;118:578-83.

[21] Smulders SA, Smeenk FWJM, Janssen-Heijnen MLG, Postmus PE. Actual and predicted postoperative changes in lung function after pneumonectomy. A retrospective analysis. Chest 2004;125:1735-41. 